\title{
Reply to "Embodied Rhythm" by Bruno Repp and "Do Preferred Beat Rate and Entrainment to the Beat Have a Common Origin in Movement?" by Laurel Trainor
}

\author{
NEIL P. McANGUS TODD \\ University of Manchester \\ CHRISTOPHER S. LEE \\ University of Manchester
}

\begin{abstract}
Two leading issues raised in commentaries on the authors' earlier article (2007) involved the possible roles of gender differences and the vestibular system on test results. Those issues are discussed in this reply.
\end{abstract}

Submitted 2007 June 28; accepted 2007 June 29

KEYWORDS: rhythm, perception, beat induction, anthropometrics

BRUNO Repp (2007) suggests there may be a closer relationship between action and perceptual judgements than between such judgements and static properties of the body, since action (in the form of locomotion) is the (main) link between anthropometry and perception. We find his suggestion plausible, and in retrospect think it would have been interesting to investigate the relationship between preferred tempo and the preferred cadence of walking (step/stride frequency per unit time). (We think cadence rather than walking speed is the variable of interest, as it is most likely to directly reflect the underlying rhythmic behaviour). No such study has ever been carried out, to our knowledge, though there have been a number of studies which have investigated the relationships between cadence (and other gait parameters) and anthropometric variables. The results are inconclusive. The classic study of Murray et al. (1964) (see also Murray et al., 1970) found no relationship between cadence and height, but it is likely that their experimental method would have obscured any such relationship (subjects underwent pretrial pacing at a fixed cadence in order to reduce cadence variability and enable meaningful comparisons of gait patterns); indeed they present an analysis of raw data from an earlier study by Fischer (see Murray et al., 1964, for references and discussion), which yields the expected inverse relationship, and suggest that differences in experimental method underlie the different results. Two later studies (MacDougall \& Moore, 2005; Samson et al., 2001) find weak, marginally significant (inverse) relationships between cadence and height, and even weaker, nonsignificant (inverse) relationships between cadence and weight. One of the difficulties facing all such studies is controlling for the myriad non-anthropometric factors influencing gait parameters, including culture (see, e.g., AlObaidi et al., 2003), and features of the physical environment (Hangland \& Cimbalo, 1997), even down to the length of the walkway (Öberg et al., 1993).

The main question raised by Repp concerns our failure to find a sex difference in our sample, which he rightly describes as a challenge to our results. We suspect, however, that an explanation may be found in biomechanical and/or physiological differences between the sexes. It is well-known that there are differences in frame structure, most notably in the pelvic region, which produce sex differences in the mechanics of walking and running (Ferber et al., 2003; Kerrigan et al., 1998; Smith et al., 2002), though it is not yet clear what effect they have on gait parameters. Further, the basal/resting metabolic rates are lower in females than in males (Harris and Benedict, 1918), in part at least due to the higher ratio of muscle mass to body fat in males (McArdle et al., 1981). Given longstanding evidence that time estimation and production speed up with increasing metabolic rate (see Weardon \& Penton-Voak, 1995, for a review), it is possible for this reason alone that preferred beat rates should in general be higher in males than females of comparable body size (and therefore also in obese, compared to non-obese, individuals). Hence in spite of anthropometric sex differences, it may be that differences in metabolism, structure and mechanics result in a distribution in the natural modes of gait that are not significantly different between the sexes.

With regards the commentary by Laurel Trainor (2007) on the possible role of the vestibular system in auditory rhythm perception we agree that this may well indeed be the case, as we have speculated for some time (Todd 1993; 1999). There is now considerable evidence that the vestibular 
apparatus, and in particular the otolith organs, are sensitive to sound and vibration (Todd 2001; Todd \& Cody, 2000; Todd et al. 2000, 2003, 2007). Thus a sense of movement may be transmitted directly without any overt movement on the part of the listener, subject to the condition that the sound intensity is above the threshold of sensation (about $70 \mathrm{~dB}$ and $30 \mathrm{~dB}$ sensation level for air-conducted and boneconducted sound respectively). However, vestibular acoustic sensitivity is a property inherited from anamniotes (fish and frogs) where the otolith organs are the primary organs of hearing and is present in all vertebrates (Todd and Merker, 2004; http://www.acoustics.org/press/151st/Todd.html ). We are therefore unable to agree with Trainor that this is unique to humans.

\section{REFERENCES}

Al-Obaidi S., Wall, J.C., Al-Yaqoub, A., \& Al-Ghanim, M. (2003). Basic gait parameters: A comparison of reference data for normal subjects 20 to 29 years of age from Kuwait and Scandinavia. Journal of Rehabilitation Research and Development, Vol. 40, No. 4, pp. 361-366.

Ferber, R., McClay-Davies, I., \& Williams $3^{\text {rd }}$, D.S. (2003). Gender differences in lower extremity mechanics during running. Clinical Biomechanics, Vol. 18, pp. 350-357.

Hangland, A., \& Cimbalo, R.S. (1997). Human ethology: Age and sex differences in mall walking. Perceptual and Motor Skills, Vol. 85, No. 3 Pt.1, pp. 845-846.

Harris, J.A., \& Benedict, F.G. (1918). A biometric study of human basal metabolism. Proceedings of the National Academy of Sciences of the United States of America, Vol. 4, No. 12, pp. 370-373.

Kerrigan, D.C., Todd, M.K., \& Croce, U. (1998). Gender differences in joint biomechanics during walking: A normative study in young adults. American Journal of Physical Medicine and Rehabilitation, Vol. 77, pp. 2-7.

MacDougall, H.G., \& Moore, S.T. (2005). Marching to the beat of the same drummer: The spontaneous tempo of human locomotion. Journal of Applied Physiology, Vol. 99, pp. 1164-1173.

McArdle, W.D., Katch, F., \& Katch, V. (1981). Exercise Physiology: Energy, Nutrition and Human Performance. Philadelphia, PA: Lippincott, Williams and Wilkins.

Murray, M.P., Drought, A.B., \& Kory, R.C. (1964). Walking patterns of normal men. Journal of Bone and Joint Surgery, Vol. 46, pp. 335-360.

Murray, M.P., Kory, R.C., \& Sepic, S.B. (1970). Walking patterns of normal women. Archives of Physical Medicine and Rehabilitation, Vol. 51, No. 11, pp. 637-650.

Öberg, T., Karsznia, A., \& Öberg, K. (1993). Basic gait parameters: Reference data for normal subjects 10-79 years of age. Journal of Rehabilitation Research and Development, Vol. 30, No. 2, pp. 210-223.

Repp, B. (2007). Embodied rhythm: Commentary on "The contribution of anthropometric factors to individual differences in the perception of rhythm, " by Neil P. McAngus Todd, Rosanna Cousins, and Christopher S. Lee. Empirical Musicology Review, Vol. 2, No. 1, pp. 14-16.

Samson, M.M., Crowe, A., de Vreede, P.L., Dessens, J.A.G., Duursma, S.A., \& Verhaar, H.J.J. (2001). Differences in gait parameters at a preferred walking speed in healthy subjects due to age, height and body weight. Aging - Clinical and Experimental Research Vol. 13, pp. 16-21.

Smith, L.K., Lelas, J.L., \& Kerrigan, D.C. (2002). Gender differences in pelvic motions and center of mass displacement during walking: stereotypes quantified. Journal of Women's Health and GenderBased Medicine, Vol. 11, No. 5, pp. 453-458.

Todd, N. P. McAngus. (1993). Vestibular feedback in music performance. Music Perception, Vol. 10, No. 3, pp. 379-382. 
Todd, N.P.McAngus. (1999). Motion in music: A neurobiological perspective. Music Perception, Vol. 17, No. 1, pp. 115-126.

Todd, N.P.McAngus (2001). Evidence for a behavioural significance of saccular acoustic sensitivity in humans. Journal of the Acoustical Society of America, Vol. 110, No. 1, pp. 380-480.

Todd, N.P.McAngus, \& Cody, F. (2000). Vestibular responses to loud dance music: A physiological basis for the "rock and roll threshold"? Journal of the Acoustical Society of America, Vol. 107, No. 1, pp. 496-500.

Todd, N.P.McAngus, Cody, F., \& Banks, J. (2000). A saccular origin of frequency tuning in myogenic vestibular evoked potentials?: Implications for human responses to loud sounds. Hearing Research, Vol. 141, pp. 180-188

Todd, N.P.McAngus, Rosengren, S.M., \& Colebtach, J.C. (2003). A short latency vestibular evoked potential produced by bone-conducted sound. Journal of the Acoustical Society of America, Vol. 114, No. 6, pp. 3264 - 3272.

Todd, N.P.McAngus, \& Merker, B. (2004). Siamangs exceed the saccular threshold: Intensity of the song of Hylobates syndactylus. Journal of the Acoustical Society of America, Vol. 115, No. 6, pp. 3077 - 3080 .

Todd, N.P.McAnugs, Cousins, R., \& Lee, C.S. (2007). The contribution of anthropometric factors to individual differences in the perception of rhythm. Empirical Musicology Review, Vol. 2, No. 1, pp. 14-16.

Trainor, L. (2007). Do preferred beat rate and entrainment to the beat have a common origin in movement? Empirical Musicology Review, Vol. 2, No. 1, pp. 17-20.

Weardon, J.J., \& Penton-Voak, I.S. (1995). Feeling the heat: Body temperature and the rate of subjective time, revisited. Quarterly Journal of Experimental Psychology: Comparative and Physiological Psychology, Vol. 48B, pp. 129-141. 